\title{
A Escrita da Viagem: Realidade e Representação em Elio Vittorini e José Cardoso Pires*
}

\section{Wander Melo Miranda}

Tem a realidade o fascínio dum tesouro escondido? (Carlos de Oliveira - Finisterra)

(...) e il viaggio era anche conversazione, era presente, passato, memoria e fantasia (...)

(Elio Vitorrini - Conversazione in Sicilia)

Elio Vittorini, na Itália, e José Cardoso Pires, em Portugal, instauram novas coordenadas no âmbito da produção literária neo-realista, contribuindo, cada um a seu modo, para o alargamento das preocupações temáticas e formais do neo-realismo. ${ }^{1}$

A originalidade e a força da obra de ambos, no contexto literário em que se atualiza, permitem-nos o estabelecimento de reflexões bastante pertinentes no que se refere, sobretudo, à relação entre realidade e representação literária. Vinculadas, de maneira específica, ao referencial externo, para o qual apontam e do qual

* Este artigo foi originalmente apresentado como trabalho final do curso «Literatura Portuguesa Contemporânea: o romance neo-realista» (Doutoramento - $1^{\circ}$ semestre de 1982 - USP) ministrado pela Prof" Doutora Maria Aparecida de Campos Brando Santilli.

1. Ressalte-se que Vittorini publica alguma de suas obras mais significativas antes mesmo da afirmação definitiva do movimento neo-realista italiano, o que viria a acontecer, sobretudo, na década de 40 . 
ao mesmo tempo se afastam, Conversazione in Sicilia ${ }^{2}$ e $O$ Hóspede de $J o b^{3}$ - textos-objeto deste trabalho - oferecem-nos a possibilidade de uma fecunda leitura comparativa.

Vittorini, em $C S$, aplica-se, segundo Bertacchini, "ad avventure locali, regionali, al sogno poniamo della libera terra siciliana, per poi tendere ad affetti più vasti, al "melodramma" di una Italia, parte simbolica del mondo offeso".4 Tenha-se presente que, para Vittorini, literatura melodramática é aquela capaz de orientar-se tanto em direção de exigências políticas quanto de exigências poéticas, diferenciando-se, porém, claramente, dos apelos da praxis política. Assim, em $C S$, ao lado da denúncia da miséria e da opressão vigentes em um espaço geográfico e historicamente bem delimitado, o Autor consegue fazer com que o problema do fascismo e do anti-fascismo se transfira, no dizer de Salinari, "dal piano della politica a quello della morale, dal piano della Storia a quello delle categorie universali". ${ }^{5}$ A intenção de evitar que prevaleçam os aspectos documental e mesmo autobiográfico da narrativa torna-se explícita na nota conclusiva do livro (cuja transcrição aqui nos parece oportuna):

Ad evitare equivoci o fraintendimenti avverto che come il protagonista di questa Conversazione non è autobiografico, cosí la Sicilia che lo inquadra e accompagna è solo per avventura Sicilia; solo perché il nome Sicilia mi suona meglio del nome Persia o Venezuela. Del resto immagino che tutti i manoscritti vengano trovati in una bottiglia. (CS, p. 192).

2. VITTORINI, Elio. Conversazione in Sicilia. Turim, Einaudi, 1981. Publicada inicialmente em Letteratura, 1938-1939 e republicada em livro, em 1941. Daqui para a frente, passa a ser indicada com a sigla $C S$.

3. PIRES, José Cardoso. O Hóspede de Job. $4^{n}$ ed. Lisboa, Moraes, 1970. Será indicado, a partir de agora, com a sigla $H J$.

4. BERTACCHINI, Renato: Elio Vittorini. In: Letteratura Italiana: $i$ contemporanei. Milão, Marzorati, 1963. p. 1515.

5. SALINARI, Carlo. Profilo storico della letteratura italiana. Roma, Editori Riuniti, 1972, p. 293, vol. III. 
Essa postura assemelha-se à de Cardoso Pires em $H J$, quando adverte aos leitores, no final de tal obra, de não visar à preocupação documental, devendo o seu texto ser antes considerado como uma "história de proveito e exemplo (...) com o objetivo de um tom sentencioso, exemplar" ( $H J$, p. 254). Isso, entretanto, não anula, ainda segundo o Autor, a possibilidade de serem estabelecidas semelhanças com a experiência da vida real. A concepção romanesca de $H J$ resulta, pois, no dizer de Alexandre Pinheiro Torres, "de o seu Autor ter circulado numa dada área e de aí ter colhido as sínteses, os conflitos fundamentaos e as alegorias que explicam os conflitos que nela se desenrolam, sem thes desprezar quaisquer parcelas". 6

Cremos ser justamente essa perspectiva não redutora do texto à sua referencialidade externa que representa um avanço e uma inovação em relação aos pressupostos rígidos de um primeiro neo-realismo, o que torna possível a aproximação analítica de Vittorini e Cardoso Pires.

Ousamos avançar, no momento, na efetivacão da nossa proposta de leitura, apesar de reconhecermos a precariedade a ela inerente. Far-se-ia necessário, inicialmente, um estudo comparativo abrangente das premissas teóricas e das producoões literárias neorealistas portuguesas e italianas, o que esclareceria muitos pontos ainda obscuros e estabeleceria, de modo sistemático, efetivas linhas de convergência e de divergência - pesquisa monumental, mas que se torna cada dia mais urgente.

Por outro lado, não visamos a discutir aqui, teoricamente, a questão da literatura realista, o que demandaria o estudo pormenorizado das relações entre mímesis e realidade, tarefa já executada exaustivamente por outros e a qual nada teríamos de novo a acrescentar. ${ }^{7}$ Basta registrar que concordamos com a posição

6. TORRES, Alexandre Pinheiro. Romance: o mundo em equagäo. Lisboa, Portugália, 1967. p. 281.

7. Vejam-se, entre nós: SANTILLI, Maria Aparecida. Arte e representação da realidade no romance português contemporâneo. São Paulo, Quíron, 1979 (principalmente, o capítulo «A obra literária como representacão») e LIMA, Luiz Costa. Realismo e Literatura. In: A metamorfose do silêncio. Rio de Janeiro, Eldorado, 1974 e, mais recentemente, Mímesis $e$ modernidade; formas das sombras. Rio de Janeiro, Graal, 1980. 
de Costa Lima que, entendendo função referencial como função semiológica, conceitua a "obra de dominância realista" como aquela "em que o referencial codivide sua importância com a codificação verbal. O que vale dizer, em que o sentido não é captável sem o conhecimento dos sistemas simbólicos não verbais aí presentes". ${ }^{8}$

Isso posto, a nossa opção pelo tratamento da problemática da viagem em $H J$ e $C S$ justifica-se não apenas por ser ela a invariante fundamental das duas narrativas em questão, mas, especialmente, por ser através dela que se torna mais evidente o processo tensional caracterizador do sentido textual, que se funda, como já foi aludido anteriormente, pelo registro do real (externo) e, ao mesmo tempo, pela sua superação no horizonte metafórico engendrado pela e na escrita.

A viagem remete também à escrita enquanto busca dẽ um procedimento discursivo apto a atualizar no seu interior as intenções do Autor, explicitadas nas notas finais acrescidas a ambos os textos, as quais funcionam, ressalte-se, não como imposição de limites de leitura, mas, ao contrário, como possibilidade efetiva de abertura. Isso, contudo, tornar-se-á mais claro somente no momento em que abordarmos as referências ao ato de escrever inseridas, diretas e/ou indiretamente, no corpus narrativo de $H J$ e $C S$.

\section{I}

A viagem de Silvestro, o narrador-protagonista de $C S$, perfaz o percurso de dois significados que ora se repelem, ora se atraem:

a) périplo pela Sicília da infância, mitificada pela memória, em direção, portanto, ao passado - viagem de recuperação e de reconhecimento e,

b) viagem à realidade crua da Sicília do presente - viagem de conscientização e de perda das ilusões do passado. Ao lado da busca da identidade individual, inscrita no seio da família (encontro com a mãe), a busca de sua inscrição ativa como sujeito no

8. LIMA, Luiz Costa. Realismo e Literatura. op. cit., p. 42. 
espaço histórico-social. Entre a partida e o término da viagem, - narrador cumpre as três etapas principais (correspondentes, grosso modo, às $2^{n}, 3^{a}$ e $4^{a}$ partes das cinco em que se subdivide a narrativa) do seu itinerário, ou seja, do particular para o geral e deste para a conscientização reflexiva, correlata à alusão ao ato de escrever.

A travessia, na balsa, do continente para a ilha funciona, metaforicamente, como o instante inicial de travessia da "fantasia" para a "realidade", termos ainda não distintos, de maneira decisiva, no âmbito da consciência da personagem. A deglutição prazerosa do queijo siciliano desperta-lhe sensações da infância, obstinadamente idealizada pela repetição insistente da frase "non c'è formaggio come il nostro" (cf. CS, p. 16-17) e remete-nos a uma Sicília idilicamente concebida, à qual se contrapõe a Sicília dos operários, trabalhadores e camponeses, companheiros de viagem - ambas deglutidas no transcorrer da narrativa. O deslocamento de Silvestro se acentua mais diante da perplexidade e do espanto desses em vista de refeição em hora tão inusitada. Nos diálogos então encetados a respeito do ato de comer, sobressai-se a fala do pequeno plantador siciliano, obrigado a se alimentar tão somente das laranjas que não consegue vender nunca, o que ilustra, de modo contundente, o problema da exploração do camponês sem terra pelos grandes proprietários, da mobilidade forçada em busca de meios de subsistência:

- E non sempre c'è il pane - disse il siciliano. - Se uno non vende le arance non c'è il pane. E bisogna mangiare le arance... cosí, vedete? (...)

- All'estero non ne vogliono, - continuò il piccolo siciliano. - Come se avessero il tossico. Le nostre arance. E il padrone ci paga cosí. Ci dà le arance ... E noi non sappiamo che fare. Nessumo ne vuole. Veniamo a Messina, a piedi, e nessuno ne vuole... Andiamo a vedere se ne vogliono a Reggio, a Villa San Giovanni, e non ne vogliono... Nessuno ne vuole. (CS, p. 21-22) 
Termo, literal e metafórico, da travessia, o testemunho do camponês é a primeira consideração de tal teor inserida no texto e que assinala, de certo modo, os caminhos a serem por ele percorridos. Ao problema da fome e da exploração, já delineado, alia-se um outro elemento a ele congruente - a repressão -, exemplificado pelo diálogo dos policiais Senza Baffi e Coi Baffi (note-se a intenção caricatural nos nomes), para quem "ogni morto di fame è un uomo pericoloso" ( $C S$, p. 24), capaz de "darsi anche alla delinquenza politica" (id. ib.) .

A possibilidade de mudança na díade fome-dominação é dada na narrativa, após os eventos citados, pela reflexão do Gran Lombardo, que influenciará decisivamente as reflexões posteriores do narrador e que se resume na postulação de uma nova consciência, desalienante:

- Credo che l'uomo sia maturo per altro, - disse.

- Non soltanto per non rubare, non uccidere, eccetera, e per essere buon cittadino... Credo che sia maturo, per altro, per nuovi, per altri doveri. E questo che si sente, io credo, la mancanza di altri doveri, altre cose, da compiere... Cose da fare per la nostra coscienza in un senso nuovo. ( $C S$, p. 32$)$.

Realizada a primeira travessia, o encontro de Silvestro com a mãe configura a etapa inicial da verdadeira viagem significante - "credevo di essere entrato a viaggiare in una quarta dimensione" ( $C S$, p. 45), declara o narrador - e intensifica a relação entre passado e presente. O desencadeamento do processo metafórico da viagem é correlato, pois, à função simbólica aglutinadora representada pela figura materna. $\mathrm{O}$ simbolismo da mãe remete ao da terra, ambas receptáculos e matrizes da vida, mas ambas ambivalentes: representação da segurança, do abrigo, do calor e da alimentação, por um lado, e do risco de opressão pela estreiteza do meio e do aniquilamento por um prolongamento excessivo da função de nutriz e de guia, por outro. ${ }^{9}$

9. Cf. CHEVALIER, Jean \& GHEERBRANT, Alain. Dictionnaire des symboles. Paris, Seghers, 1974. 
A viagem para dentro da família, em direção ao passado e ao eu do narrador, corresponde a um "retorno à origem", a uma nova fecundação e a um novo nascimento. Assim, a mãe é "madre uccello dell'aria e, nelle sue uova, della luce, che dà la luce" $(C S$, p. 75$)$, "madre-ape" ( $C S$, p. 81), e relaciona-se à assimilação visceral da terra siciliana, pelo narrador, explicitada pela interiorização do cheiro de "corrube" da pensão de Vizzini: "dormii lá, profondo come sotterra (...) mi alzai l'indomani, fatto anche di corrube, con quell'odore ormai in me" ( $C S$, p. 44, grifos nossos).

A imersão no passado implica, contudo, o seu controle e domínio e, ao mesmo tempo, possibilita a emersão dos "meios" necessários à compreensão do presente. Assim, o ângulo de visão do narrador é ampliado e ele passa a ver mais intensamente, ou seja, "due volte reale" ( $C S$, p. 57), o mundo que o circunda e que se concretizará nas visitas em companhia da mãe, às casas dos doentes da aldeia. A etapa inicial, para dentro, acrescenta-se, pois, uma nova etapa, para fora, e "il viaggio in Sicilia [ha] una nuova ripresa" ( $C S$, p. 91).

A cada doente visitado, a mãe, após aplicar-lhe a injeção, procura informar-se da alimentação a ele ministrada e instaura-se, então, a ladainha "fúnebre" da fome. ${ }^{10}$ Confirma-se, desse modo, pela repetição, a permanência do estado de penúria vivenciado no

10. Vejam-se alguns exemplos:

a) «(..) Che avete mangiato oggi?

- Ho mangiato una cipolla, - la voce dell'uomo rispose.

- Era una buona cipolla, - disse la voce della donna.

- Gliel'ho arrostita nella cenere.

- Bene, - mia madre disse. - Dovreste dargli anche un uovo.

- Domenica gliel'ho dato, - disse la voce della donna» (CS, p. 93)

b) «E mia madre chiese:

- Che le avete dato da mangiare?

- Le daremo la cicoria, stasera, - rispose la voce ch'era dell'uomo». (CS, p. 96)

c) «Mia madre chiese:

- Ha mangiato?

Le donne indicarono il secchio [di chiocciole] e la piú anziana rispose:

- Si, ha mangiato». (CS, p. 101) 
passado pelo narrador, quando era obrigado a recorrer, constantemente, para matar a fome (como os que se lhe oferecem à contemplação, no presente), aos caramujos, à chicória selvagem e mesmo aos insetos (cf. CS, cap. XII). Assim, a visão exterior, idílica, da Sicília é contraposta à sua dolorosa visão interna:

A questo modo viaggiavamo per la piccola Sicilia ammonticchiata; di nespoli e tegole e rumore di torrente, fuori; di spiriti, dentro, nel freddo e nel buio. ( $C S$, p. 98)

A escuridão, literal e metafórica, das miseráveis casas cavadas na rocha (às quais se opõe a casa, na aldeia, da rica amante de um "Gran Signore") não permite a identificação de rostos individuais. Quando tal ocorre (e isso apenas uma vez), o Silvestropersonagem vê nos olhos do doente apenas "il genere umano ch'essi erano" ( $C S$, p. 102), o que provoca no Silvestro-narrador as reflexões sobre o "mondo offeso" (cf. os belíssimos capítulos XXVI e XXVII). Essas reflexões representam o momento primordial de maturação da consciência do narrador-personagem e ampliam o alcance significante da narrativa, estendendo o registro da experiência vivenciada à metáfora textual dos marginalizados de todas as sociedades, em todos os tempos.

Uma das resultantes mais significativas desse processo é a compreensão exata do passado, seja pela descoberta da dimensão real do avô e do pai ("Non Macbeth, non re", CS, p. 111), seja pelo distanciamento de uma Sicília "fabulosa", "livresca", como as Mille e una notte das leituras da infância (cf. CS, p. 124). $\overline{\mathbf{E}}$ proposta, portanto, in fieri, uma nova concepção de leituraescritura da "Sicília", e entramos na etapa derradeira da viagem.

O guia de Silvestro não é mais, significativamente, a mãe, mas Calogero, o amolador de facas cujo discurso apela sempre para a ação reformadora, como se pode depreender da citação a seguir:

- Non avete da arrotare una spada? Non avete da arrotare un cannone? (...) - Qualche volta $\mathrm{mi}$ sembra basterebbe che tutti avessero denti e unghie da farsi arrotare. Li arroterei loro come denti di vipera, come unghie di leopardo... (CS, p. 131 e 133) 
$\widehat{\mathrm{E}}$ por intermédio de Calogero que Silvestro vai ao encontro de Ezechiele, perfazendo uma trajetória que equivale, simbolicamente, à do "aquilone" da infância (cf. $C S$, cap. XXXII), descida "nel cuore puro della Sicilia ( . . ) avendo il cuore dell'infanzia, siciliana e di tutto il mondo" ( $C S$, p. 139), em busca da solidariedade, da remissão de uma nova humanidade, a dos humilhados e ofendidos, cuja história Ezechiele - espelho do narrador - escreve:

L'uomo Ezechiele si mise a riepologare: - Il mondo è grande ed è bello, ma è molto offeso. Tutti soffrono ognuno per se stesso, ma non soffrono per il mondo che è offeso e cosí il mondo continua ad essere offeso ( . . ) - E hai detto al nostro amico, - egli disse - che io scrivo sui dolori del mondo offeso? (...) Digli che come un eremita antico io trascorro qui i miei giorni su queste carte e che scrivo la storia del mondo offeso. Digli che soffro ma che scrivo, e che scrivo di tutte le offese una per una, e anche di tutte le facce offensive che ridono per le offese compiute e da compiere. (CS, p. 141-142)

Vê-se que, ao se aproximarem do fim, viagem e escrita se identificam como faces complementares de um mesmo processo: o ponto de chegada da viagem de Silvestro delineia o ponto de partida do narrador pela escrita-viagem que testemunha e denuncia o sofrimento humano dos oprimidos, cristalizado, no final da narrativa, no enigmático monumento da mulher de bronze: a História impassível ante os mortos que a celebram; cada morto uma página legada ao esquecimento, uma medalha no seu peito de mãe (terra) devorada que se nutre de cadáveres como os corvos que, significativamente, sobrevoam a aldeia (cf. $C S$, cap. XLIV).

A dinâmica do tempo que aponta para o futuro como possibilidade de transformação desfaz-se (como é sugerido pela morte do jovem irmão de Silvestro, na guerra) e reduz-se à estaticidade do tempo parado - . "La Sicilia era divenuta ferma" (CS, p. 176) ; "Sicilia non piú viaggio" (CS, p. 184). A escrita cabe, apenas, o papel de funcionar como um dos meios de "lavare le offese del mondo e dissetare l'uman genere offeso". ( $C S$, p. 150) 


\section{I I}

Em $H J$, a escrita da viagem focaliza dois itinerários diversos:

a) o de Aníbal e Portela, de Cimadas até Cercal Novo, em busca de trabalho - viagem de luta pelos meios de sobrevivência - e,

b) o do coronel Gallagher e seus assessores, no interior do país, em tréinamento militar — viagem de exercitação dos mecanismos de dominação. Registrados simultaneamento pelo narrador, esses dois itinerários convergem para a determinação do sentido textual, inscrevendo-o no âmbito geral das relações entre opressor e oprimido.

Desde o capítulo inicial evidencia-se a questão da viagem. Na taberna de Cercal Novo, o cabo Três-Dezasseis irrita-se diante dos apitos do comboio, que lhe sugerem a idéia de movimento e liberdade. A noção de mobilidade instaura-se, pois, em oposição à imobilidade, literal e metafórica, que Cercal Novo, com seu quartel, representa, como é sugerido pela figura do tendeiro: "Não pensaria por certo em viagens e em comboios - estava e está como sempre: sentado numa indiferença de pedra" ( $H J$, p. 11). Entretanto, Cercal Novo - espaço fechado do alheamento e da imobilidade - é circundado por um espaço mais amplo, o dos campos "varridos pelos ventos da fome" ( $H J$, p. 32), por onde circulam gaibéus, ratinhos e malteses. A imbricação significante desses dois espaços é atualizada na narrativa através da movimentação neles efetuada pelos "caminheiros" Aníbal e Portela, personagens centrais da escrita-viagem.

Toda e qualquer ação que efetivamente se proponha como possibilidade, ainda que remota, de contraposição aos mecanismos engendradores do estado de penúria vigente, culmina na repressão que faz emergir a passividade como conduta geral desejável processo ilustrado de maneira exemplar na narrativa pelo episódio da prisão de Floripes e da reação solitária da avó Casimira.

Desse modo, o som dos cavaleiros armados na praça de Cimadas não só indica o "livro aberto" ( $H J$, p. 42) da realidade vivenciada que se oferece "com uma clareza terrível" (id. ib.) à 
"leitura" dos jogadores da taberna, como também propicia a abertura para a compreensão globalizante dos lances fundamentais do jogo escritamrealidade-leitura proposto pela narrativa. ${ }^{11}$

O velho Aníbal, um dos jogadores, contrapõe à realidade presente os feitos gloriosos do antigo "livro dos portugueses". ( $H J$, p. 61), em cujas páginas se misturam, como na sua memória, mouros, vivandeiras, conquistas. Endereçado ao passado (é significativa, no caso, a posição estrutural ocupada pelos jogadores na narrativa: literal e metaforicamente de costas para a praça com os soldados), Aníbal não é capaz de efetuar, com a clareza necessária, a leitura do novo livro dos portugueses, cujas páginas os eventos narrativos de $H J$, vivenciados por ele, incumbem-se de preencher (daí o fato de, por exemplo, ao contrário da velha Casimira, Aníbal não perceber que os mouros hoje são outros.) (Cf. $H J$, cap. II)

Desde o início, portanto, o itinerário da viagem de Aníbal e Portela, em busca do filho-soldado e de trabalho, inverte ("perverte") a direção daquele de um de seus folhetos preferidos contendo os seguintes dizeres: "Rompia a manhã sobre os limoeiros do castelo quando as aias do poderoso Yacub, da bela cidade de Ulisses, anunciaram em alvoroço a armada dos garbosos lusitanos..." (HJ, p. 62) Ironicamente, a garbosa Lusitânia do presente, obliterada por Aníbal, reduz-se aos malteses esfomeados perseguidos pelos soldados, a Floripes e ao camponês presos, mantidos e interrogados como animais, ao elenco frio dos rios dos compêndios escolares que o soldado lê (cf. $H J$, p. 67-68).

A contundência da problemática da fome e suas ramificações significantes evidencia-se, desde a etapa inicial da viagem, pelo registro do aspecto desolador da paisagem física e humana: campos ressequidos; escassez de água e caça; Portela jovem, mas carcomido pela doença; Aníbal levando como um alimento precioso um cágado, que remete aos ratos comidos na China dos mandarins (e a referência, como se vê, não é gratuita). Após o capítulo $\mathrm{XV}$, que narra o ataque convulsivo de Portela e o seu alívio, em busca de "nuvens e luz" ( $H J$, p. 135), tem-se, no capítulo XVI, a visão de

11. Sobre o jogo em $H J$, veja-se: TORRES, op. cit., p. 279-282. 
um peneireiro - "uma ave familiar que representa a majestade da força livre e a calma imensa da planície" ( $H J$, p. 144) - que Gallagher, o coronel americano, pensa ser um condor.

O relevo desses dois momentos narrativos justifica-se, aqui, pelo fato de eles determinarem o ponto nodal de uma ampla rede metafórica, de crucial importância no texto, que abrange, sobretudo, a metáfora do pássaro e da caça, cujos pólos aglutinadores são justamente Portela e Aníbal, de um lado, e Gallagher, do outro. Assim, estabelece-se a série opositiva alto/baixo, liberdade/ confinamento, esclarecedora da relação dominador/dominado, como se verá a seguir.

Nas dunas vizinhas ao polígono de tiro, no qual se dá a visão do peneireiro, Aníbal e Portela deparam-se com uma velha esquelética e maltrapilha e com garotos em disputa pelos estilhaços das granadas: a velha é um "espantalho negro" (HJ, p. 150), "um pássaro pica-flor aos saltinhos" (HJ, p. 153); já um dos garotos, trepado numa árvore, assemelha-se a um pássaro de "asas partidas" ( $H J$, p. 159) . . Ligando-se a força livre do peneireiro, as asas partidas do garoto e o ferimento da perna posteriormente amputada de Portela, temos, desde já, os primeiros delineamentos do traçado da rede metafórica anteriormente mencionada. Após a detonação do primeiro tiro, a euforia do cel. Gallagher transparece na sua "boca rasgada de orelha a orelha" ( $H J$, p. 164), congruente ao seu "estômago de avestruz" ( $H J$, p. 224), à sua "sede constante" (id. ib.). Juntem-se a isso a imagem da terra (que, após as explosões, apresenta-se tal qual um "peixe ferido" ( $H J$, p. 164) e as crianças, homens e velha estendidos na duna como "um pequeno lago de rosto a boiar à tona das cinzas de pólvora" (id. ib.) - à maneira de cadáveres (metafóricos). Tal quadro possibilita-nos a percepção de quem é o caçador, a ave de rapina, quem a caça, a presa oferecida à rapinagem.

A metáfora do peixe, introduzida no capítulo XIX, sofre um "crescendo" à medida que prosseguimos na leitura através dos elementos apresentados no capítulo seguinte. Aí é narrado o encontro de Casimira e Floripes na cadeia que ocupa o lugar onde outrora era a sacristia da igreja da vila. Essa superposição espacial 
sugere a coligação efetivada entre o poder terreno e os representantes do poder supra-terreno no tocante ao funcionamento dos mecanismos de dominação, alargando o tom de denúncia da narrativa, como é denotado pelo trecho da epístola aos coríntios sempre citado pelo sapateiro preso — "'nada será digno de espanto já que o próprio Satanás se transformou em anjo de luz...'” ( $H J$, p. 176). A fachada da sacristia, o seu exterior, permanece imutável e esconde o seu interior, inutilmente, porém, porque a santa ali "ficou queimada e seca, com a aparência de uma camponesa de sol a sol" (HJ, p. 172). Curiosamente, nessa parte da narrativa, os presos são comparados a pescadores, pois, nos dias de missa recebem esmolas em sacolas "que desciam e subiam, na ponta de um fio, como anzóis de pescadores" ( $H J$, p. 171).

$\overrightarrow{\mathrm{E}}$ indubitável a importância do elemento peixe no cristianismo, já que simboliza, ao lado do pão, a refeição eucarística. A eucaristia, além de símbolo de união, refeição de toda a comunidade de Israel (que, por sinal, excluía a participação de estrangeiros), é também uma celebração em "memória", isto é, uma renovada celebração da libertação de Israel do Egito. Acresça-se, finalmente, que o seu simbolismo fundamental é o de uma refeição sacrifical, em que os participantes entram em contacto com o sacrifício comendo do sacrificado. ${ }^{12}$

O ato sacrifical que a narrativa denuncia inverte, contudo, o significado de união e/ou celebração de libertação: a pesca do polvo, presenciada por Gallagher torma-se a imagem mais evidente disso: "Então, com um dedo ágil e sábio, dão-lhe volta ao saco da cabeça e adeus polvo, adeus monstro voraz, que ficaste para sempre cego e inutilizado" ( $H J$, p. 228, grifos nossos). A amplitude metafórica dessa cena pode ser melhor percebida quando relacionada à venda da espoleta a Gallagher por Angelina, fato lembrado significativamente por ele diante da visão do polvo e cuja função simbólica é explicitada pelo narrador:

12. Cf. VAN DEN BORN, A. Dicionário enciclopédico da Biblia. Petrópolis, Vozes, 1971. p. 508-510. 
A venda da espoleta à porta do Café Moderno teve, se quisermos, o seu lado simbólico. Foi, por assim dizer, um acto de entrega, o gesto de uma criança da localidade para com um hóspede de honra, acompanhado de toda a corte de majores e de capitães. (HJ, p. 203)

Note-se que a venda da espoleta que os meninos carregam como se fosse um "pássaro vivo" (HJ, p. 200) ocorre após a amputação dá perna do Portela. O ato simbólico da venda não é, portanto, apenas a capitulação diante do futuro (impossível) representado pelas crianças e pelo jovem Portela mutilado - verdadeiro amuleto de guerra - (ressalte-se, ainda, que Angelina encontra, ironicamente, os militares no Café Moderno, "matando o tempo" (HJ, p. 200). E ele, antes, o resultado mais contundente da conquista-dominação da viagem de Gallagher. O apelido FIRST KISS dado por ele à espoleta - "o primeiro beijo das novas peças de guerra nas terras onde principia a Europa" ( $H J$, p. 229) busca revestir idilicamente o processo de dominação, camuflando a violência da posse a ele inerente, denunciada, no entanto, pelo estado a que ficou reduzido, literal e metaforicamente, o Portela, na etapa final da sua viagem, agravante do seu estado inicial, antes da partida. ${ }^{13}$

Portela, a caça-alimento do dominador, é, na enfermaria, um "defunto ao Iuar, farejado por vultos curiosos" (HJ, p. 179); os enfermeiros são, por sua vez, "chacais de bata branca, parceiros da morte a cobiçarem-lhe a carne" (HJ, p. 196). Após a cirurgia, no delírio provocado pela anestesia, Portela codifica oniricamente a realidade circundante e, através de deslocamentos e condensações (Aníbal como o chacal, a invasão de cágados com unhas e dentes afiados, etc.), o texto do seu sonho ilumina o texto maior em que se insere. Assim é que o término da operação cirúrgica coincide com o término da operação militar: "Acabou o fogo, acabou o fogo', comentava-se por todo o lado” ( $H J$, p. 198).

13. O resultado final da viagem de Portela e Anibal reflete-se, especularmente, nos títulos dos folhetos possuídos pelo velho: A História dos Whouros e A Verdadeira Tragédia dos Tavoras e o Fim Cruel Que Lihes Deu o Rei. 
Indubitavelmente é Portela o ponto fulcral da mensagem a ser decodificada - "pequenino papel, uma mensagem lançada numa cisterna" ( $H J$, p. 195) ; "a folha branca, esse sinal vivo" $(H J$, p. 196) —, o signo aglutinador das intenções da narrativa. Em sonhos, Portela vê-se como uma largatixa mutilada, congruente à sua imagem no jardim, como "um pobre de pedir que se arrasta pelas feiras" ( $H J$, p. 213). A cena em que tal imagem é configurada é de suma importância pela posição estrutural nela ocupada por Gallagher e Portela: no alto e à frente, Gallagher, entregue à redação do seu "diário de bordo", escrita dos seus feitos de conquistador; no fundo e no baixo, Portela, imagem do conquistado (inutilizado como o polvo do capítulo imediatamente posterior a esse episódio):

A páginas tantas, Galagher bebeu uma golada de whisky e veio à janela tomar alento. Lá em baixo, pregado num muro de cicatrizes, Job contemplava, com olhos mudos, o cair da tarde e os pássaros que saltitavam à sua volta. ( $H J$, p. 216)

Esse único momento em que se faz referência ao Jó do título do livro é de importância capital: $H J$ reescreve, contextualiza, num espaço-tempo determinado, os elementos principais ao livro bíblico de Jó. Ora, justamente nele predomina o tema da integração do sofrimento da existência humana e do aspecto absurdo e caótico da vida diante da razão do Homem ${ }^{14} \mathrm{O}$ texto de Cardoso Pires, evidentemente, não endossa a entrega aos desígnios sobrehumanos como possibilidade de saída, mas a resistência corajosa e paciente ante a adversidade. "Paciência de Jó", diz um aforismo popular; paciência-resistência, termo final com que se conclui a escrita-viagem pela fala de Portela, agora no Iugar do filho-soldado de Aníbal, mas um filho-soldado da pátria mutilado(a):

"Tio Aníbal", disse João Portela, erguendo-se na enxerga onde outrora dormira o filho-soldado. "Alcanceme a muleta, tenha paciência". ( $H J$, p. 251)

14. Cf. VAN DEN BORN, A. op. cit., p. 790-794. 
Resistência quer dizer também voltar para Cimadas, seguir em direção à terra natal, embora o hóspede indesejado permaneça ocupando um lugar que não the pertence. O problema da posse da terra pelos seus legítimos donos resolve-se apenas em sentido "metafórico": Aníbal, no caminhão, de volta, é apenas "um velho num berço de palhinha e a terra a fugir por baixo dele, imagine-se" ( $H J$, p. 235, grifos nossos) ; Portela tenta, literal e metaforicamente, ainda de maneira rudimentar, dominar a direção do novo caminho a ser seguido: "Bordejava (...) como um barco de um só remo" (HJ, p. 237) .

"Escrita da navalha" ( $H J$, p. 239), a concepção romanesca de $H J$ amalgama ilusão (os folhetos) e realidade (o pão incerto), desvendando o verdadeiro significado de um espaço-tempo encoberto pela retórica do poder — "o País (...) e, à margem de tudo, uma cama de enfermaria encravada na dureza de um quartel" ( $H J$, p. 209). O procedimento de trazer ao espaço central da cena do texto justamente aqueles colocados à margem pela sociedade implica o registro de eventos "históricos" facilmente identificáveis, mas que adquirem, pelo tratamento que lhes dá o Autor, um aspecto generalizador e exemplar.

\section{V}

O cotejo das leituras dos dois textos considerados possibilita-nos arrolar as semelhanças e diferenças que em ambos determinam a configuração do tema da viagem. CS e $H J$ assemelham-se, sobretudo, por serem romances exemplares de aprendizagem: tanto Silvestro, em $C S$, quanto Aníbal e Portela, em $H J$, são viajantesaprendizes. Vivendo intensamente a experiência do real, sofrem eles transformações significativas que lhes permitem perceber, em gradações diversas, seus limites e suas possibilidades enquanto integrantes de uma ordem social que alija do seu interior toda ação contestatória. Nesse caso, é necessário ressaltar uma diferenca importante entre o protagonista de $C S$ e os protagonistas de $H J$ : estes experimentam diretamente os efeitos da opressão que os imobiliza, enquanto àquele essa experiência é dada indiretamente. Daí procede, a nosso ver, uma outra variante, relativa 
à estruturação de ambas as narrativas. Referimo-nos, especialmente, à presença, em $C S$, e à ausência, em $H J$, de reflexões sistemáticas do narrador, problema evidentemente correlato à diferença do foco narrativo dos dois textos.

As reflexões algo constantes que interrompem o fluxo narrativo de CS participam, harmônica e coerentemente, da economia. textual, na medida em que resultam, na narrativa, da relação imediata com os acontecimentos vivenciados e/ou contemplados pelo narrador, e não de uma imposição onipotente, "panfletária", pois o questionamento do contexto social é também, em $C S$, autoquestionamento do narrador como sujeito nele inserido e como produtor de "linguagem". Assim, a escolha da perspectiva em $1^{\text {a. }}$ pessoa facilita, no caso, a plena realização do projeto narrativo do Autor: ao leitor é apresentada uma experiência já vivenciada, mas que se presentifica in fieri ante seus olhos durante o desenrolar da escrita, exigindo-lhe não uma postura contemplativa e passiva, mas a sua participação ativa - como numa conversação.

Esse aspecto dialógico de $C S$ acha-se também presente, embora de modo diverso, em $H J$. A opção pelo foco narrativo em $3^{\text {a }}$ pessoa explica a ausência de reflexões do narrador em $H J$, as quais, se presentes, poderiam invalidar a "repercussão" da matéria ficcional. Visto não ser o narrador participante dos acontecimentos narrados, a presença de reflexões como sucede em $C S$ poderia dar ao texto um caráter dogmático e monológico (de resto, tão comum nas produções neo-realistas), incidindo justamente naquilo que ele procura combater. ${ }^{15}$

Finalmente, um elemento comum aproxima $C S$ e $H J$, como procurou-se evidenciar neste trabalho: a plena realização formal dos dois textos e a interação coerente entre intenção autoral e produção ficcional.

15. Isso não impede que, pelas interferências do autor implícito, passiveis de serem detectadas no texto, possa ser percebido o sistema de valores que o texto endossa e/ou propōe (sobre a diferença entre autor implicito e narador, Cf. BOOTH, Wayne C. A retórica da ficçäo. Lisboa, Arcádia, 1980). 